\title{
HDlive of the Fetal Heart
}

\author{
${ }^{1}$ Toshiyuki Hata, ${ }^{2}$ Kenji Kanenishi, ${ }^{3}$ Uiko Hanaoka, ${ }^{4}$ Hirokazu Tanaka
}

\section{ABSTRACT}

We present the latest HDlive echocardiographic studies on the fetal heart using spatiotemporal image correlation (STIC). Fetal HDlive echocardiography with the use of new skin-like colors provides sonographers and physicians with a natural and anatomically realistic appearance of the fetal heart. Moreover, HDlive images provide entirely new visual experiences for obstetricians and pediatric cardiologists owing to the anatomically realistic depiction of the normal fetal heart and fetal congenital anomalies in utero. This novel technique may assist in the evaluation of the fetal cardiac anatomy, and offer potential advantages relative to conventional two-, three-, and four-dimensional fetal echocardiography. HDlive may be an important modality in future fetal cardiac research and in the evaluation of fetal congenital heart disease.

Keywords: HDlive, Spatiotemporal image correlation, Fetal echocardiography, Surface-rendering mode, Inversion mode, Fetal heart, Normal anatomy, Congenital heart anomaly.

How to cite this article: Hata $T$, Kanenishi $K$, Hanaoka $U$, Tanaka H. HDlive of the Fetal Heart. Donald School J Ultrasound Obstet Gynecol 2014;8(3):266-272.

\section{Source of support: Nil}

\section{Conflict of interest: None}

\section{INTRODUCTION}

HDlive is a new surface-rendering mode that uses an adjustable light source providing the ability to create lighting and shadowing effects, thereby increasing depth perception. ${ }^{1}$ HDlive provides such extraordinarily realistic imaging of the embryo and fetus that it is almost impossible to differentiate between actual photographs and ultrasound scans. ${ }^{2,3}$ There have been several reports, including embryonic, fetal, placental, and umbilical cord HDlive images. ${ }^{4-9}$ HDlive images obtained using both adjustable lighting and the new skin-like colors also present fetal, placental, and umbilical cord abnormalities with anatomically realistic features similar to those seen in gross specimens. ${ }^{10-18}$

${ }^{1}$ Professor and Chairman, ${ }^{2,4}$ Associate Professor, ${ }^{3}$ Lecturer

${ }^{1-4}$ Department of Perinatology and Gynecology, Kagawa University School of Medicine, Kagawa, Japan

Corresponding Author: Toshiyuki Hata, Professor and Chairman Department of Perinatology and Gynecology, Kagawa University School of Medicine, 1750-1 Ikenobe, Miki, Kagawa 7610793, Japan Phone: +81-0878912174, Fax: +81-0878912175, e-mail: toshi28@ med.kagawa-u.ac.jp
There have been only two reports on fetal HDlive echocardiographic evaluations of the normal fetal heart and congenital heart anomalies. ${ }^{19,20}$ HDlive with spatiotemporal image correlation (STIC) provides entirely new visual experiences for obstetricians and pediatric cardiologists owing to the anatomically realistic depiction of normal and abnormal fetal cardiac structures of the beating heart. ${ }^{19}$ The present paper presents fetal HDlive echocardiographic studies on normal and abnormal fetal cardiac structures, and, based on them, makes recommendations for future research and the application of fetal HDlive echocardiography regarding the antenatal diagnosis of congenital heart anomalies and fetal cardiology research.

\section{SURFACE RENDERING}

\section{Normal Heart}

\section{Four-chamber View}

The dynamic motion of the flap of the foramen ovale was evident (Figs 1 to 2B). Opening and closing of both atrioventricular valves were clearly identified in systole and diastole (see Figs 2A and B). Each papillary muscle was also noted. The orifice of the pulmonary vein was sometimes recognized (see Fig. 2A).

\section{En-face View}

Each leaflet of the atrioventricular valves and each cusp of the aortic and pulmonary valves were identified in the

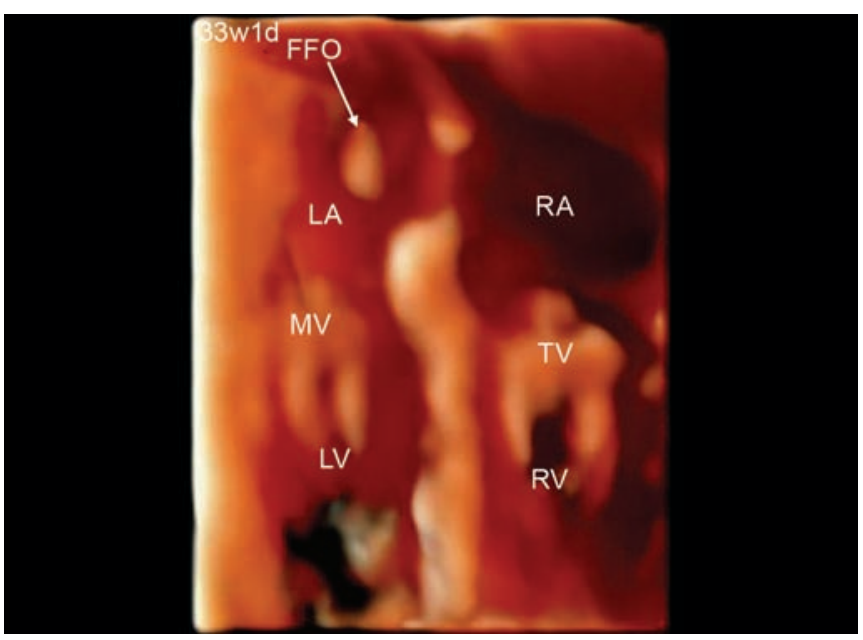

Fig. 1: HDlive image of the four-chamber view in a normal fetal heart at 33 weeks and 1 day of gestation (FFO: Flap of foramen ovale; LA: Left atrium; LV: Left ventricle; MV: Mitral valve; RA: Right atrium; RV: Right ventricle; TV: Tricuspid valve) 

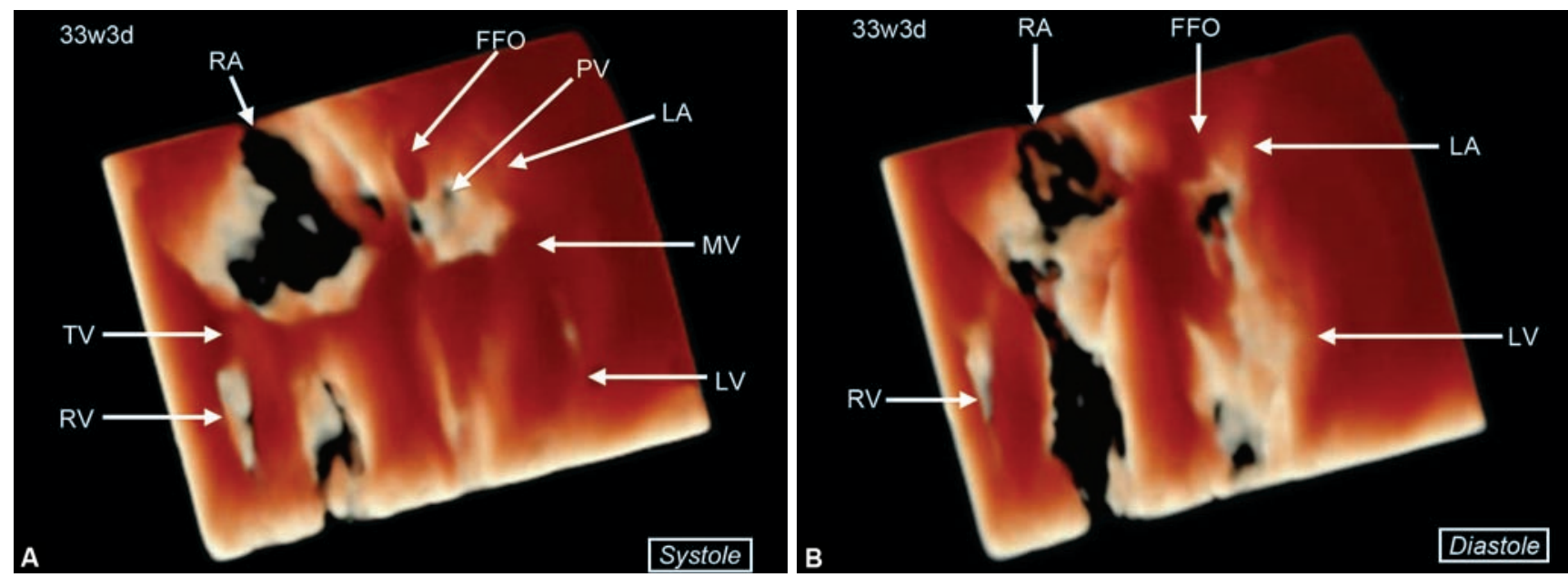

Figs 2A and B: HDlive images of the four-chamber view in systole $(A)$ and diastole $(B)$ in a normal fetal heart at 33 weeks and 3 days of gestation (FFO: Flap of foramen ovale; LA: Left atrium; LV: Left ventricle; MV: Mitral valve; PV: Pulmonary vein; RA: Right atrium; RV: Right ventricle; TV: Tricuspid valve)

en-face view (Figs 3 to 5B). Opening and closing of the atrioventricular, aortic, and pulmonary valves (PVS) were clearly recognized in systole and diastole (see Figs 4A to 5B). Spatial relationships among the four valves were also easily understood in this view.

\section{Interatrial and Interventricular Septum}

The unique movement of the flap of the foramen ovale (FFO) was evident in systole and diastole (Figs 6A and B). The shape and position of the foramen ovale at the interatrial septum were clearly recognized (Figs 7A and B). The smooth surface of the left interventricular septum was identified (see Fig. 7A), whereas that of the right interventricular septum was slightly rough compared to the left-sided surface (see Fig. 7B).

\section{Congenital Heart Disease}

\section{Ventricular Septal Defect}

The shape and position of ventricular septal defect (VSD) were easily understood using HDlive (Figs 8 to 9B).

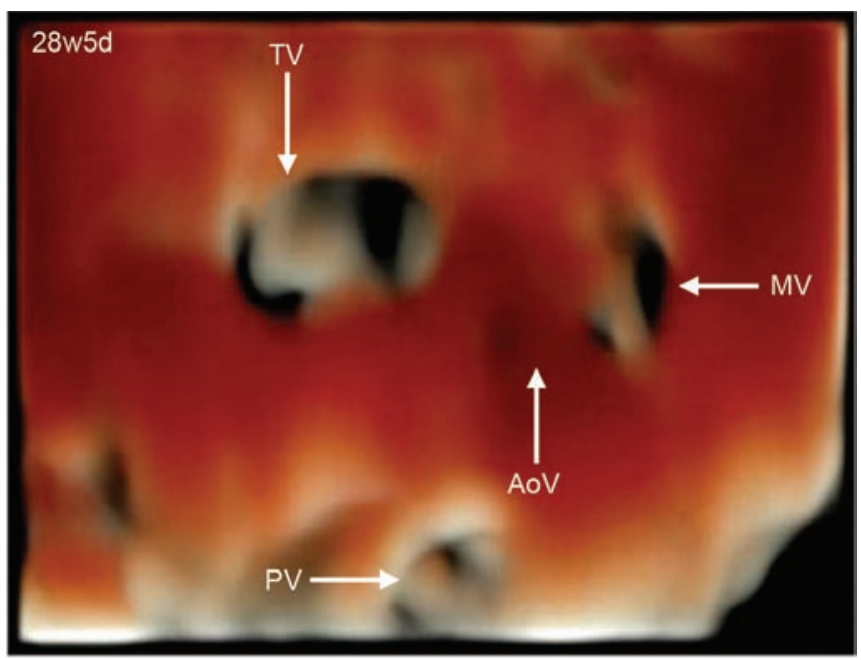

Fig. 3: HDlive image of the en-face view in a normal fetal heart at 28 weeks and 5 days of gestation. Each cusp of valves is clearly noted (AoV: Aortic valve; MV: Mitral valve; PV: Pulmonary valve; TV: Tricuspid valve)

Moreover, the change of shape in systole and diastole was also recognized (see Figs 9A and B).
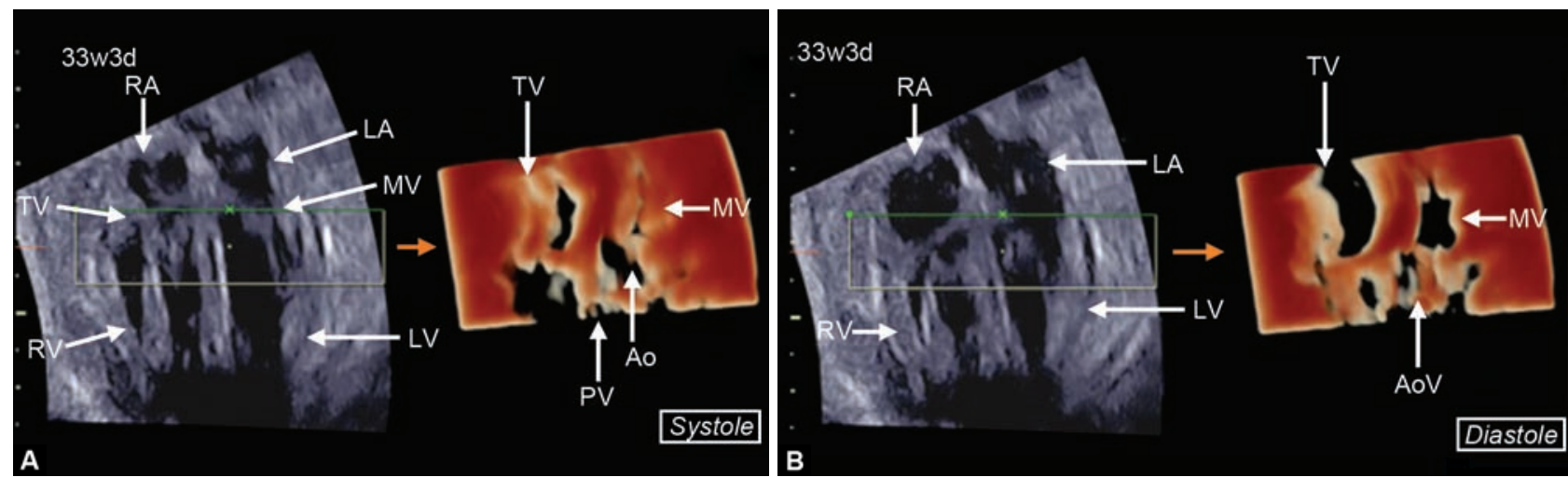

Figs 4A and $B$ : HDlive images of the en-face view in systole $(A)$ and diastole $(B)$ in a normal fetal heart at 33 weeks and 3 days of gestation (Ao: Aorta; AoV: Aortic valve; LA: Left atrium; LV: Left ventricle; MV: Mitral valve; PV: Pulmonary valve; RA: Right atrium; RV: Right ventricle; TV: Tricuspid valve) 


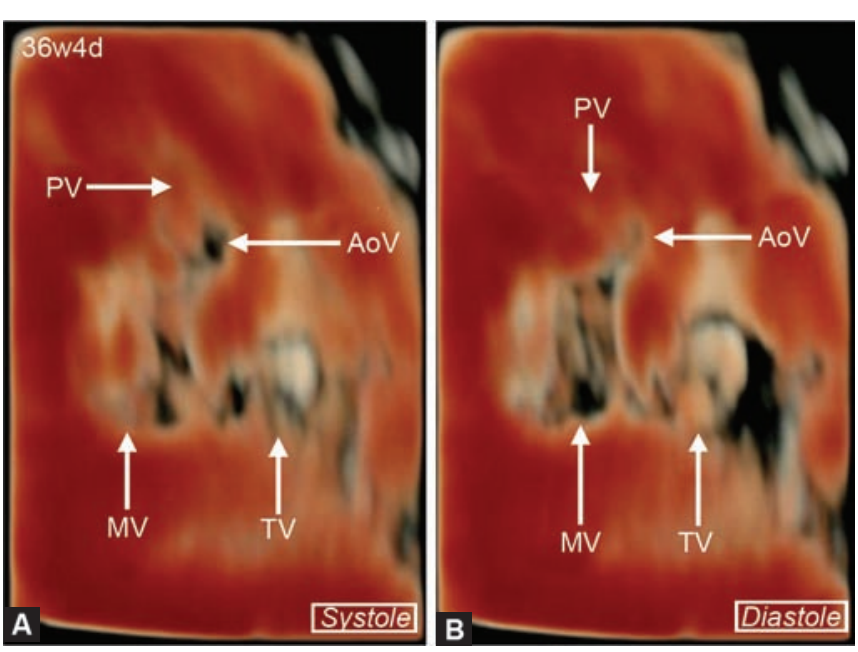

Figs $5 A$ and $B$ : HDlive images of the en-face view in systole (A) and diastole (B) in a normal fetal heart at 36 weeks and 4 days of gestation (AoV: Aortic valve; MV: Mitral valve; PV: Pulmonary valve; TV: Tricuspid valve)

\section{Tetralogy of Fallot}

In the case of tetralogy of fallot (TOF), the overriding aorta and VSD were realistically shown in the four-chamber view (Fig. 10). ${ }^{19}$ Moreover, characteristic overriding

aortic valve motion was noted using HDlive with STIC in the en-face view (Fig. 11).

\section{Pulmonary Atresia (PA) with VSD}

The overriding aorta and a very small pulmonary artery were clearly identified in the en-face view (Fig. 12). VSD was also noted.

\section{Ebstein's Anomaly}

In the case of Ebstein's anomaly, natural and anatomically realistic appearances of significantly low attachment of the tricuspid valve and the atrialized portion of the right ventricle were shown in the en-face view (Fig. 13). Moreover, elongation of the anterior cusp, shortening of the septal cusp, the atrialized portion of the right ventricle, and the inferior and apical displacement of the tricuspid valve apparatus from its annulus were shown. ${ }^{19}$ Thickened leaflets of the tricuspid valve were also noted.

\section{Hypoplastic Left Heart Syndrome}

In the case of hypoplastic left heart syndrome (HLHS), a large right ventricle and very small left ventricle with VSD
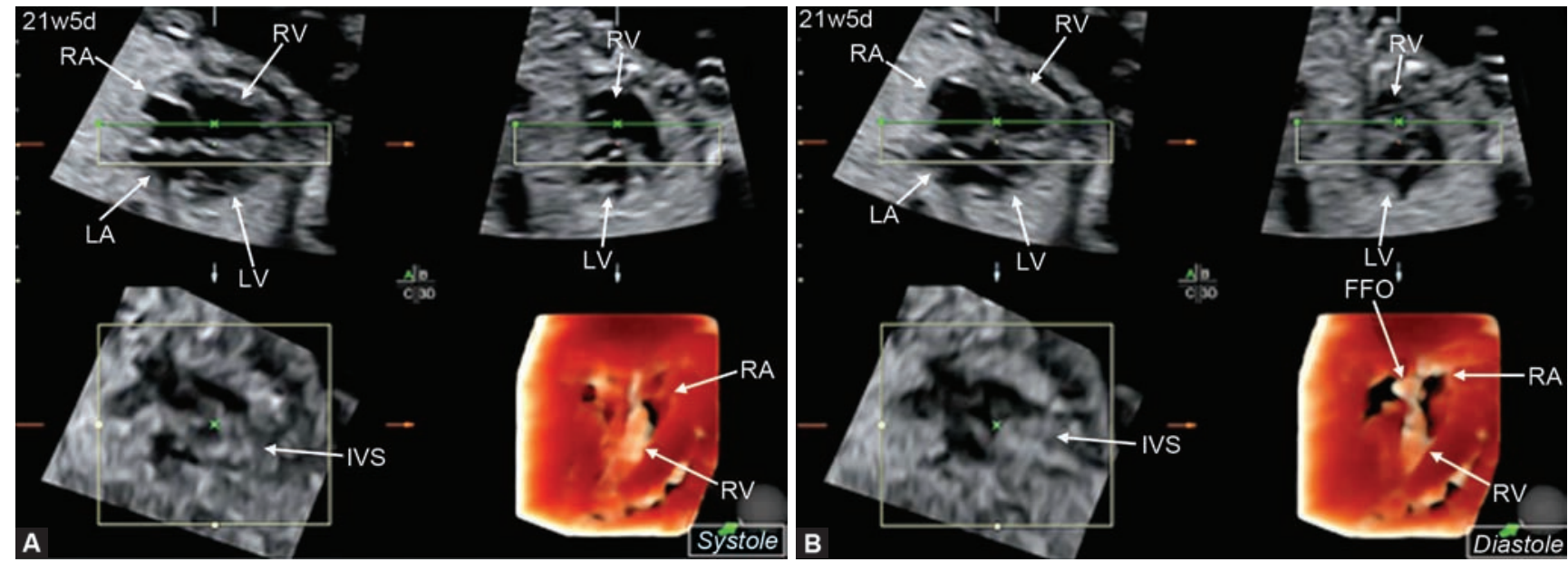

Figs $6 \mathrm{~A}$ and $\mathrm{B}$ : HDlive images of the interatrial and interventricular septum (IVS) from the right side in systole (A) and diastole (B) in a normal fetal heart at 21 weeks and 5 days of gestation (FFO: Flap of foramen ovale; LA: Left atrium; LV: Left ventricle; RA: Right atrium; RV: Right ventricle)
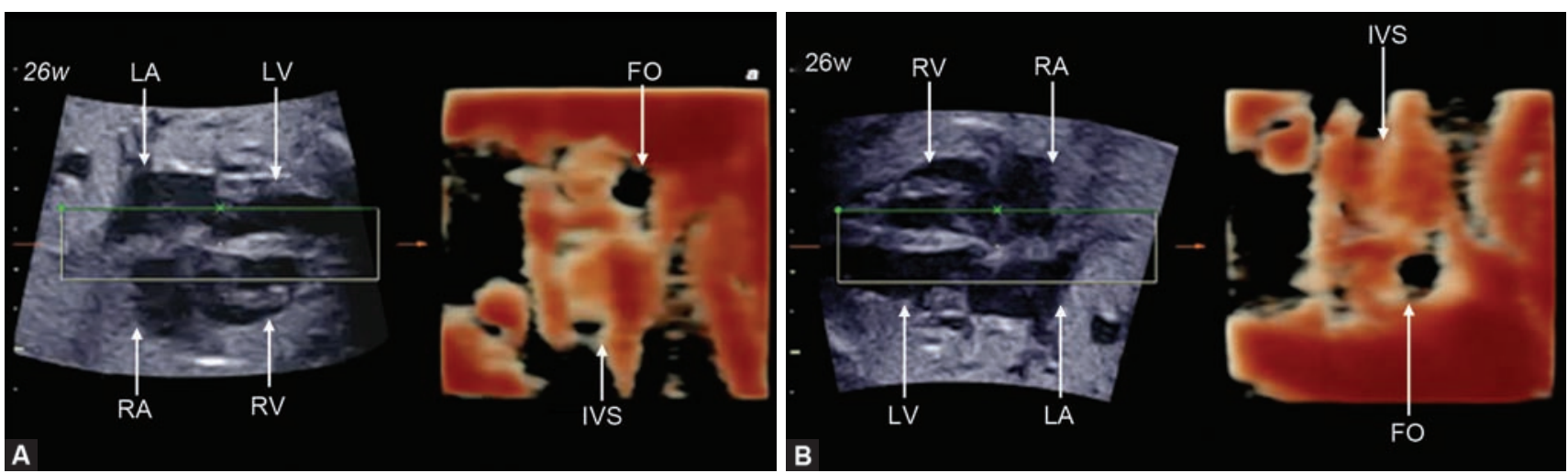

Figs 7A and B: HDlive images of the interatrial and interventricular septum (IVS) from the left (A) and right sides (B) in a normal fetal heart at 26 weeks of gestation (FO: Foramen ovale; LA: Left atrium; LV: Left ventricle; RA: Right atrium; RV: Right ventricle). A subtle difference of the surface wall of IVS between LV and RV can be recognized) 


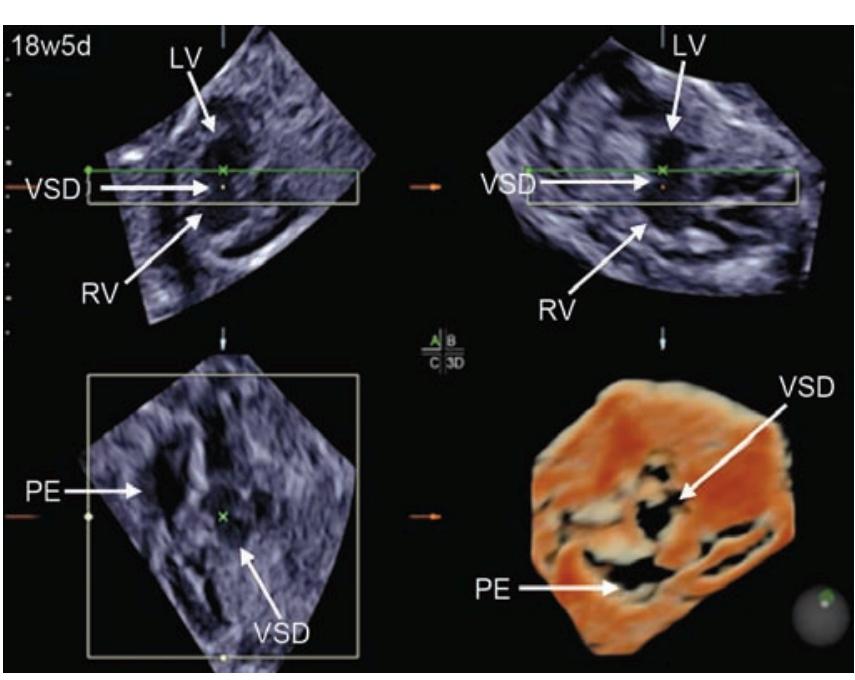

Fig. 8: HDlive image of the interatrial and interventricular septum from the left side at 18 weeks and 5 days of gestation. A large ventricular septal defect (VSD) is clearly identified (LV: Left ventricle; PE: Pericardial effusion; RV: Right ventricle) were noted in the en-face view (Fig. 14). A very small left ventricle, large right ventricle, and dysplastic pulmonary valve were also clearly shown in systole and diastole in the four-chamber view with the pulmonary artery (Figs 15A and $\mathrm{B})$.

\section{INVERSION MODE}

The HDlive inversion mode is a very unique and novel technique that provides a means of evaluating fetal cardiac outflow tracts and great vessels. This technique may assist in the evaluation of spatial relationships between the great vessels and both ventricles. It was clearly shown that the pulmonary artery crosses in front of the aorta (Fig. 16). Shunt flow through VSD was also evident (see Fig. 16). The aortic arch and descending aorta were clearly depicted (Figs 16 and 17).
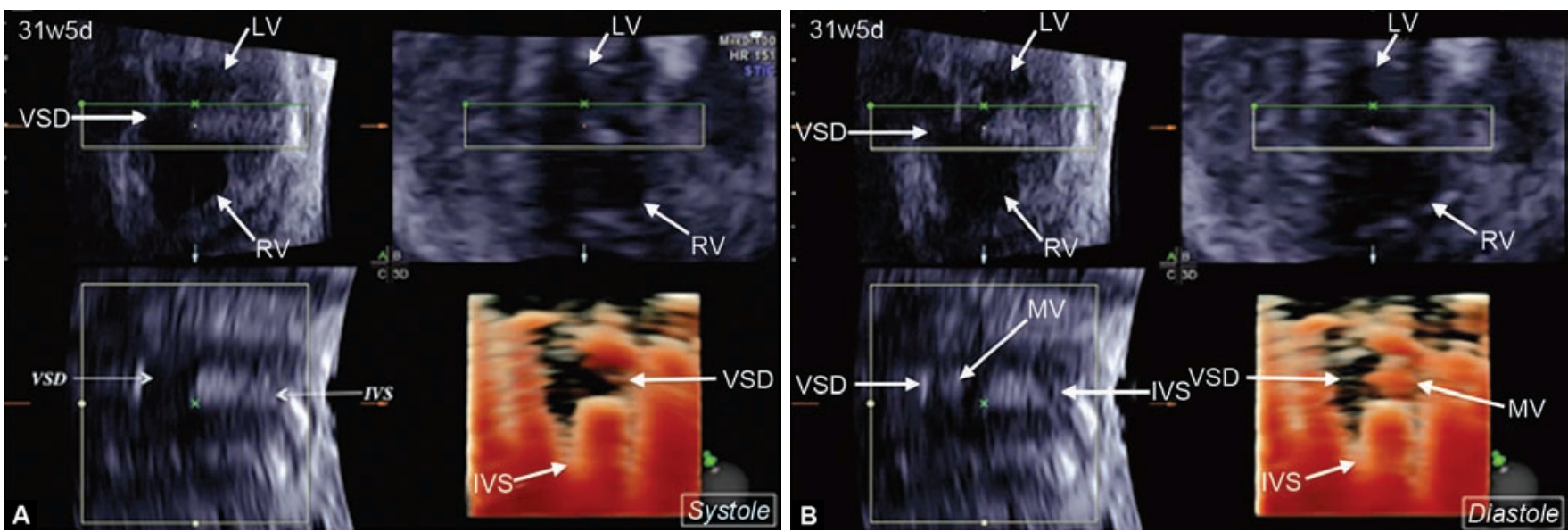

Figs 9A and B: HDlive images of the interatrial and interventricular septum (IVS) from the left side in systole (A) and diastole (B) in a fetus with ventricular septal defect (VSD) at 31 weeks and 5 days of gestation (LV: Left ventricle; MV: Mitral valve; RV: Right ventricle)

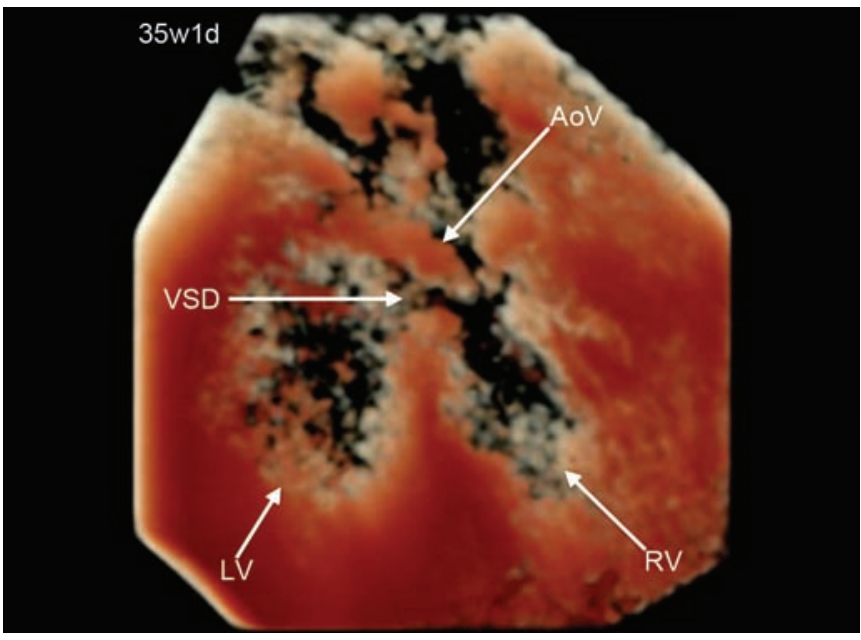

Fig. 10: HDlive image of the four-chamber view of tetralogy of fallot at 35 weeks and 1 day of gestation. An overriding aorta and a ventricular septal defect (VSD) can be noted (AoV: Aortic valve; LV: Left ventricle; RV: Right ventricle) (Courtesy: Reprinted with permission from Hata T et al) ${ }^{19}$

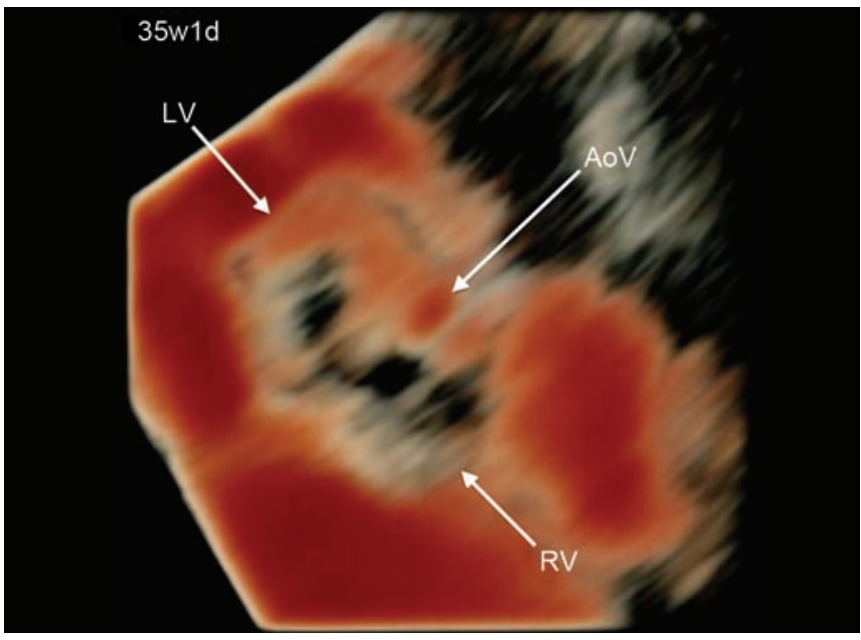

Fig. 11: HDlive image of the en-face view of tetralogy of fallot at 35 weeks and 1 day of gestation. An overriding aortic valve (AoV) is evident (LV: Left ventricle; RV: Right ventricle) 


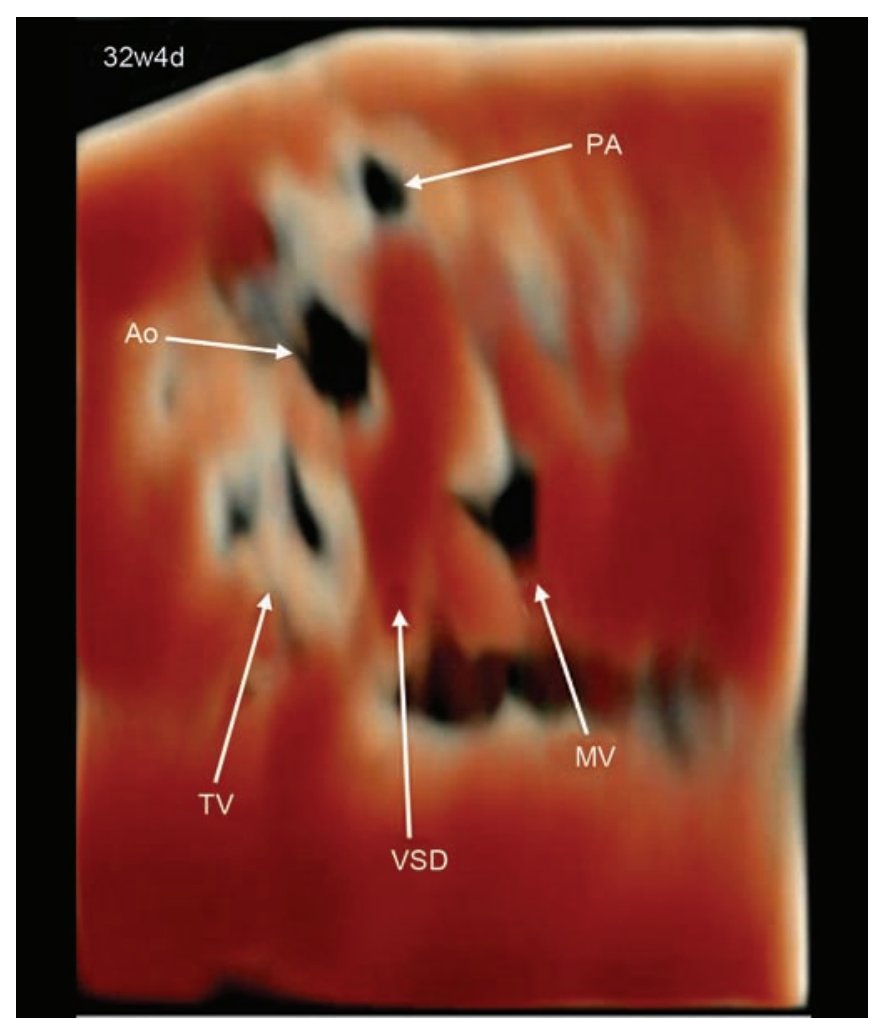

Fig. 12: HDlive image of the en-face view of pulmonary atresia with a ventricular septal defect at 32 weeks and 4 days of gestation. An overriding aorta (Ao) and very small pulmonary artery (PA) are evident (MV: Mitral valve; TV: Tricuspid valve; VSD: Ventricular septal defect)

\section{CONCLUSION}

This review article focused on HDlive studies on the fetal heart. HDlive provides clinicians with a new and realistic, and arguably much improved, view of the complexities and interrelationships of the fetal cardiac anatomy noninvasively. The influence on fetal cardiology of HDlive in echo technologies might include: (1) the generation of unique information on normal and abnormal intra-cardiac anatomy, (2) evaluation of the fetal heart in the first trimester, and (3) excellent imaging of complex congenital heart disease. The present and future application of this new modality to the prenatal diagnosis of fetuses with congenital heart disease might be promising. However, this is not to imply that HDlive will replace conventional two-, three-, and four-dimensional fetal echocardiography. This novel technique may assist in the prenatal diagnosis of fetal cardiac anomalies, and offer potential advantages relative to conventional two-, three-, and four-dimensional fetal echocardiography and color/power Doppler ultrasound.

\section{ACKNOWLEDGMENTS}

The work reported in this paper was supported by a Grant-in-Aid for Scientific Research on Innovative Areas

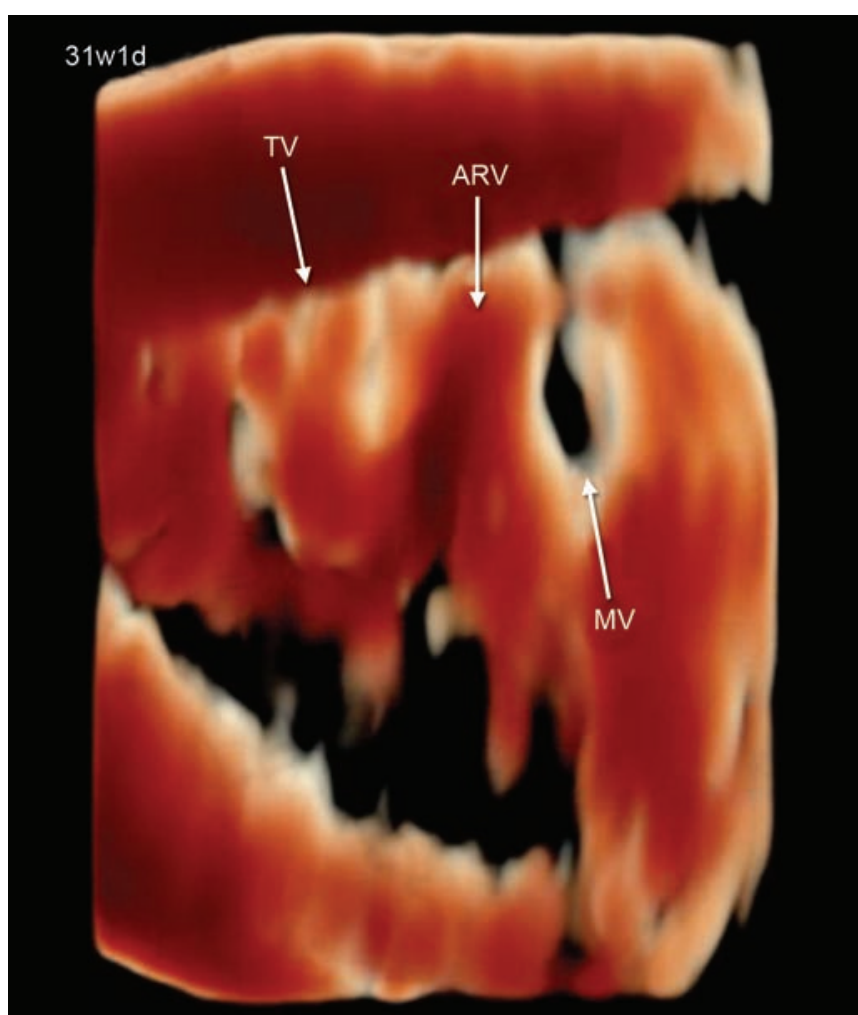

Fig. 13: HDlive image of the en-face view of Ebstein's anomaly at 31 weeks and 1 day of gestation. Thickened leaflets of the tricuspid valve (TV) and atrialized portion of the right ventricle (ARV) can be clearly noted (MV: Mitral valve) (Courtesy: Reprinted with permission from Hata $\mathrm{T}$ et al $)^{19}$

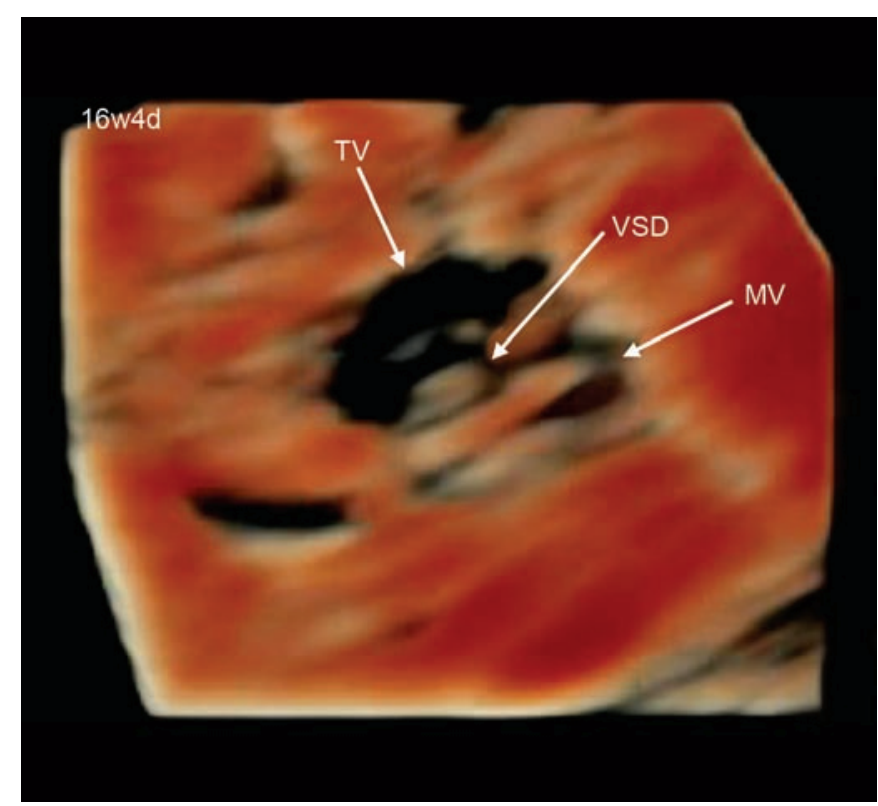

Fig. 14: HDlive image of the en-face view of hypoplastic left heart syndrome with ventricular septal defect (VSD) at 16 weeks and 4 days of gestation (MV: Mitral valve; TV: Tricuspid valve)

'Constructive Developmental Science’ (No. 24119004), and a Research Grant (No. 25462561) from The Ministry of Education, Culture, Sports, Science and Technology, Japan. 

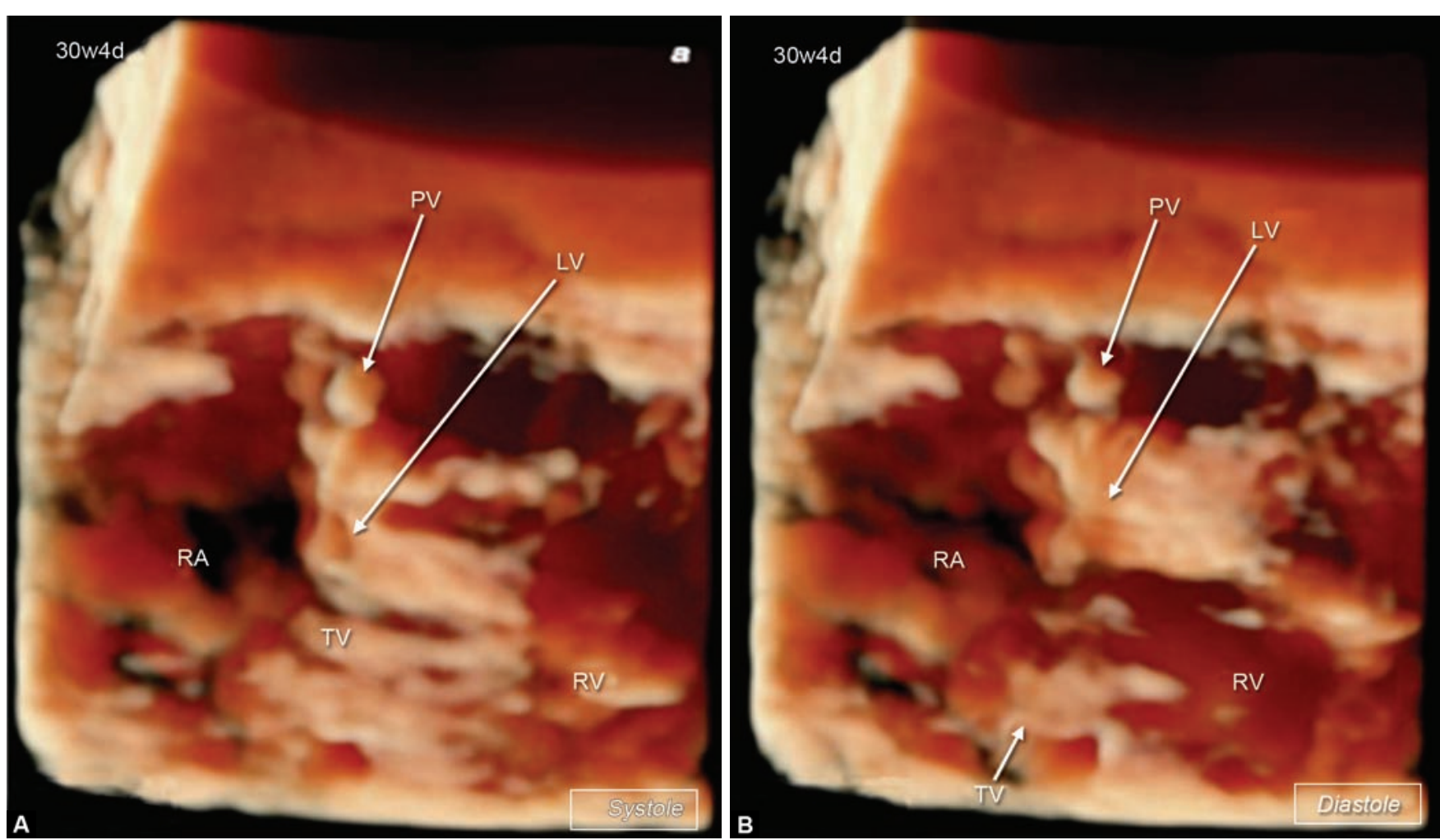

Figs 15A and B: HDlive images of the four-chamber view with pulmonary artery of hypoplastic left heart syndrome at 30 weeks and 4 days of gestation. A very small left ventricle (LV) and dysplastic pulmonary valve (PV) can be clearly noted in systole (A) and diastole (B) (RA: Right atrium; RV: Right ventricle; TV: Tricuspid valve)

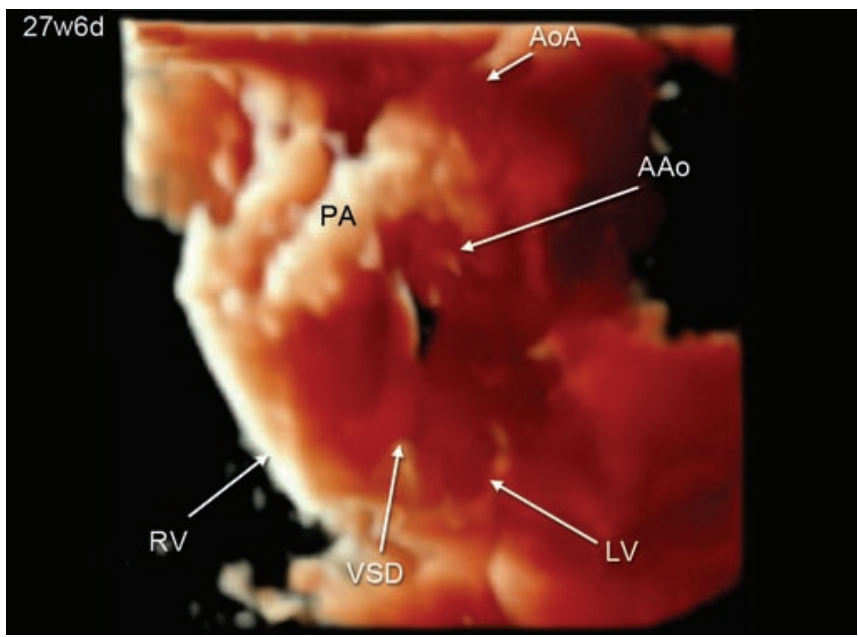

Fig. 16: HDlive image with inversion mode of the fetal heart with a ventricular septal defect (VSD). It can be clearly noted that the pulmonary artery (PA) crosses in front of the ascending aorta (AAo). Shunt flow through VSD is also evident (AoA: Aortic arch; LV: Left ventricle; RV: Right ventricle)

\section{REFERENCES}

1. Kagan KO, Pintoffl K, Hoopmann M. First-trimester ultrasound images using HDlive. Ultrasound Obstet Gynecol 2011;38:607.

2. Merz E. Surface reconstruction of a fetus $(28+2$ GW) using HDlive technology. Ultraschall Med 2012;33:211-212.

3. Hata T, Hanaoka U, Tenkumo C, Sato M, Tanaka H, Ishimura $\mathrm{M}$. Three- and four-dimensional HDlive rendering images of normal and abnormal fetuses: pictorial essay. Arch Gynecol Obstet 2012b;286:1431-1435.

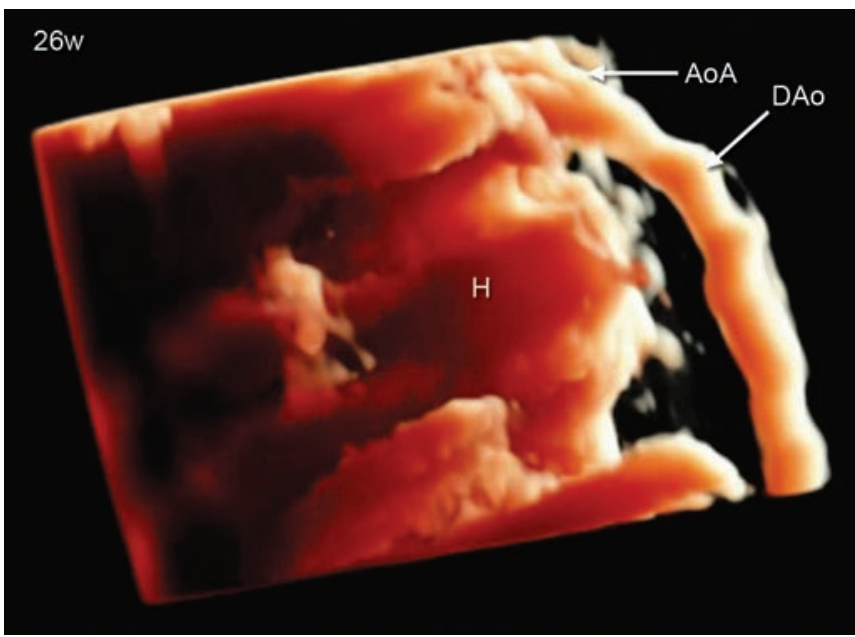

Fig. 17: HDlive image with inversion mode of the aorta (AoA: Aortic arch; DAo: Descending aorta; H: Heart)

4. Bonilla-Musoles F, Raga F, Castillo JC, Bonilla F Jr, Climent MT, Caballero O. High definition real-time ultrasound (HDlive) of embryonic and fetal malformations before week 16. Donald School J Ultrasound Obstet Gynecol 2013;7:1-8.

5. Grogore M, Mares A. The role of HDlive technology in improving the quality of obstetrical images. Med Ultrason 2013;15:209-214.

6. Bonilla-Musoles F, Raga F, Osborne NG, Bonilla F Jr, Caballero O, Climent MT, Wallraf SH, Castillo JC. Multimodality threedimensional volumetric ultrasound in obstetrics and gynecology with an emphasis in HDlive technique. Ultrasound Q 2013;29:1-13. 
7. Hata T, Hanaoka U, Mashima M, et al. Four-dimensional HDlive rendering image of fetal facial expression: a pictorial essay. J Med Ultrasonics 2013;40:437-441.

8. Hata T. HDlive rendering image at 6 weeks of gestation. J Med Ultrasonics 2013;40:495-496.

9. Tonni G, Grisolia G. Fetal uvula: navigating and lightning the soft palate using HDlive. Arch Gynecol Obstet 2013;288:239-244.

10. Hata T, Tenkumo C, Sato M, Kanenishi K, Ishimura M. Threedimensional HDlive rendered images of intrauterine abnormalities during pregnancy. J Med Ultrasonics 2012;40:179-180.

11. Tanaka T, Ito M, Uketa E, Mori N, Hanaoka U, Kanenishi K, Tanaka H, Hata T. Antenatal three-dimensional sonographic features of multicystic dysplastic kidney. J Med Ultrasonics 2012; 40:181-183.

12. Hata T, Uketa E, Tenkumo C, Hanaoka U, Kanenishi K, Tanaka $\mathrm{H}$. Three- and four-dimensional HDlive rendering image of fetal acrania/exencephaly in early pregnancy. J Med Ultrasonics 2012;40:271-273.

13. Ishibashi M, Tanaka H, Ito M, Uketa E, Mori N, Hanaoka U, Kanenishi K, Hata T. Antenatal three-dimensional sonographic diagnosis of persistent cloaca. J Med Ultrasonics 2012;40: 275-277.
14. Hata T, Hanaoka U, Tenkumo C, Ito M, Uketa E, Mori N, Kanenishi K, Tanaka H, Ishimura M. Three-dimensional HDlive rendering image of cystic hygroma. J Med Ultrasonics 2012;40: 297-299.

15. Tenkumo C, Tanaka H, Ito M, Uketa E, Mori N, Hanaoka U, Kanenishi K, Ando M, Hata T. Three-dimensional HDlive rendering images of the TRAP sequence in the first trimester: Reverse end-diastolic umbilical artery velocity in a pump twin with an adverse pregnancy outcome. J Med Ultrasonics 2012;40:293-296.

16. Merz E. 3D image of Siamese twins at $12+3$ gestational weeks. Ultraschall Med 2013;34:109.

17. Kanenishi K, Nitta E, Mashima M, Hanaoka U, Koyano K, Tanaka H, Hata T. HDlive imaging of intra-amniotic umbilical vein varix with thrombosis. Placenta 2013;34:1110-1112.

18. Hata T, Hanaoka U, Mashima M. HDlive rendering image of cyclopia and a proboscis in a fetus with normal chromosomes at 32 weeks of gestation. J Med Ultrasonics 2014;41:109-110.

19. Hata T, Mashima M, Ito M, Uketa E, Mori N, Ishimura M. Three-dimensional HDlive rendering images of the fetal heart. Ultrasound Med Biol 2013;39:1513-1517.

20. Grisolia G, Tonni G. Fetal echocardiography using HDlive. J Obstet Gynaecol Can 2013;35:497. 